\title{
Levels of Benzoic and Sorbic Acid Preservatives in Commercially Produced Ready to Serve Products in Sri Lanka
}

\section{Krishanthi Karunarathne*}

Senior Assistant Government Analyst, Government Analyst Department, Sri Lanka

*Corresponding Author: Krishanthi Karunarathne, Senior Assistant Government Analyst, Government Analyst Department, Sri Lanka.

Received: June 01, 2019; Published: July 05, 2019

DOI: $10.31080 /$ ASPS.2019.03.0329

\begin{abstract}
Benzoic acid, sorbic acid are widely used for food preservation. The analyses of these preservatives in 100 different food products were performed. Therefore 100 samples including, 10 carbonated beverages, 20 jams, 10 jelly drinks, 10 jelly cups, 30 ready to serve drinks, 10 nectars, and 10 sauces were analysed by using high performance liquid chromatography. The HPLC determination of the preservatives was performed using a reversed - phase C18 column and UV detection at $235 \mathrm{~nm}$. Flow rate approximately $1.2 \mathrm{ml} /$ min. Eluent for HPLC, mix 50 volume parts of Ammonium Acetate solution with 40 volume parts of methanol for HPLC and adjust to a pH of 4.5 to 4.6 with acetic acid. The preservative concentration in samples was used as external standards for sodium benzoate and potassium benzoate. Levels were compared with Food Act and Food Standards Regulation in Sri Lanka. Both benzoic acid and sorbic acid were detected in a range of $1120 \mathrm{ppm}$ to $30 \mathrm{ppm}$ and $582 \mathrm{ppm}$ to $16 \mathrm{ppm}$ respectively. Although $65 \%$ of the samples was not compliant with the Food Act and Food Regulations in Sri Lanka.
\end{abstract}

Keywords: Benzoic Acid; Sorbic Acid; Sri Lanka

\section{Introduction}

According to Sri Lanka Regulations preservatives are chemical substances which when added to food is capable of inhibiting, retarding or arresting the process of fermentation, acidification or other decomposition of food. Examples of preservatives which permitted specified in Sri Lanka. Benzoic acid, Sodium benzoate, Potassium benzoate, Calcium benzoate mainly

- $\quad$ Methy 4 - hydroxyl benzoate

- Methyl 4 - hydroxyl benzoate Sodium salt

- Methy 4-hydroxyl benzoate

- $\quad$ Ethyl 4 - hydroxyl benzoate Sodium salt

- $\quad$ Propyl 4 - hydroxyl benzoate

- $\quad$ Prophyl 4- hydroxyl benzoate Sodium salt

- Sodium nitrate

- $\quad$ Potassium nitrate

- Sodium nitrite

- Potassium nitrite

- Propionic acid

- $\quad$ Sodium propionate

- Calcium propionate
Another main one Sorbic acid

- Sodium sorbate,

- Potassium sorbate,

- $\quad$ Calcium sorbate and Sulphur dioxide Sodium sulphite

- $\quad$ Sodium hydrogen sulphite

- $\quad$ Sodium metabisulphite

- $\quad$ Potassium metabisulphite

- Calcium sulphite

- Calcium hydrogen sulphite

- $\quad$ Bipenyl, 2-Hydroxybiphenyl, Hexamine, Nisin.

In this study as preservatives we were used only Benzoic Acid and Sorbic acid.
Structure of Sorbic Acid (E 200)<smiles>C/C=C/C=C/C(=O)O</smiles>

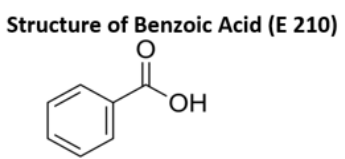

Figure 
Preservatives are chemical substances which are added to the food to prolong it's shelf - life. Inhibiting the bacterial and fungal growth as they lag the spoilage accidence. Several studies proved the mutagenicity of Sorbic and Benzoic acids. Induce mutations in human DNA (therefore their determinations in food product is a must), Intestinal upset, Allergies, Skin rashes, Headaches, Hyperactivity (already affected by children).

The long term effects also affected. Cancer induction (like bladder cancer), Respiratory problems, For these reasons the use of food additives in different countries is limited by this specific regulations. These preservatives are allowed by legislation but their use demands special care.

Like other countries the use of these preservatives in Sri Lanka also have been restricted. In Sri Lanka followed Food Act and Food Standards Regulations prepared by Food Control Administration Unit of the ministry of healthcare and nutrition in Collaboration with the World health Organization. And SLS - Sri Lanka Standards (specifications for food preservatives). This Sri Lanka Standard was authorized for adoption and publication by the Council of the Sri Lanka Standards institution on 1990 - 08 - 13. After the draft finalized by the Drafting committee on food products Divisional Committee.

The aim of this study was to determine the Sorbic and Benzoic acids in different food products. By using RP - HPLC apparatus.

Such foods are

- 10 Carbonated Beverages

- 20 Jams

- 10 Jelly drinks

- 10 jelly cups

- 10 Nectars

- 10 Sauces

- 30 Ready to Serve drinks

Because of the huge consumption of these different food products, especially by children, which intrinsically rely on the usage of these products.

Therefore there is a dire need to determine their concentrations within different food products in order to guarantee that they are within the normal ranges stated by Food Act and Food Standards Regulations in Sri Lanka.

\begin{tabular}{|l|c|c|}
\hline Product & $\begin{array}{c}\text { Food Act and } \\
\text { Regulation Ranges for } \\
\text { Sorbic Acids (mg/kg) }\end{array}$ & $\begin{array}{c}\text { Food Act and } \\
\text { Regulation Ranges for } \\
\text { Benzoic acid mg/kg) }\end{array}$ \\
\hline $\begin{array}{l}\text { Carbonated } \\
\text { Beverages }\end{array}$ & 300 & 160 \\
\hline Nectars & 300 & 160 \\
\hline Jelly Drinks & 300 & 160 \\
\hline $\begin{array}{l}\text { Ready } \\
\text { to Serve } \\
\text { Drinks }\end{array}$ & 300 & 160 \\
\hline Sauces & 1000 & 250 \\
\hline Jelly Cups & Not permitted & Not permitted \\
\hline Jam & 350 & Not permitted \\
\hline
\end{tabular}

Table 1: Clarifies the permitted ranges for sorbic and benzoic acids in above different food commodities (According to FOOD ACT and REGULATIONS in Sri Lanka).

Many methods have been validated for the Benzoic and Sorbic acids determination purpose in different food products and commodities. The proposed ISO 22855: 2008 method for determination of Benzoic and Sorbic acid Fruit and Vegetable products enables the simultaneous and selectivity for analysis. High Performance Liquid Chromatography (HPLC) has high specificity, minimum sample preparation, Does not require derivatization.

\section{Materials and Methods}

Chromatographic analysis was carried out using High Performance Liquid Chromatography Agilent 1200 series

Equipped with

- Quaternary pump

- Vacuum degasser

- UV detector

- $\quad$ Analytical column, (Supelco C18 5 m x 250 x 4.6 mm)

\section{Principle}

Benzoic and Sorbic acid are extracted from test portion using a mixture of Ammonium acetate buffer solution and methanol, under acidic condition. The concentration of Benzoic and Sorbic acid is determined by means of HPLC using a reverse phase column and ultraviolet (UV) detector. 
Reagents and Materials

- $\quad$ Acetic acid $(\mathrm{CH} 3 \mathrm{COOH})$ glacial

- $\quad$ Methanol (CH3OH) for HPLC

- Ammonium Acetate CH3COONH4, $0.01 \mathrm{~mol} / \mathrm{l}$ solution

- Ammonium acetate/Acetic acid (CH3COONH4/ $\mathrm{CH} 3 \mathrm{COOH}$ ) buffer solution.

- $\quad$ Sodium Benzoate and Sorbic acid stock solutions

- $\quad \mathrm{K} 4[\mathrm{Fe}(\mathrm{CN}) 6] .3 \mathrm{H} 2 \mathrm{O}$ and $\mathrm{ZnSO} 4.7 \mathrm{H} 20$

Extraction Solution

Mix 60 volume parts of Ammonium Acetate/Acetic acids buffer solution with 40 volume parts of methanol.

\section{Eluent for HPLC}

Mix 50 volume parts of ammonium acetate solution with 40 volume parts of methanol for HPLC and adjust to a pH of 4.5 to 4.6 with Acetic acid. Filter the eluent over membrane filter.

Sample collection

The highly consumed ready to serve products with different brands in Sri Lanka were received from public health inspectors in Health Department. A total number of 100 samples were collected, to be representative of what a highly consumer in Sri Lanka.

\section{Preparation of test solution}

Homogenize or mix the sample carefully, Concentrated juice should be diluted to single strength. Clear Samples, Dilute 5.00g to $10.00 \mathrm{~g}$ of a sample in approximately $75 \mathrm{ml}$ of extraction solution in a $100 \mathrm{ml}$ volume flask - ultrasonic bath at least $10 \mathrm{mins}$ - Dilute to the mark. Filter through a membrane syringe filters $0.45 \mathrm{~m}$.

For cloudy samples

All the procedure followed up equal to the clear sample. In additionally, Have to add

- $1 \mathrm{ml}$ of $\mathrm{K} 4[\mathrm{Fe}(\mathrm{CN}) 6] .3 \mathrm{H} 20$

- 1 mlof ZnSO4. 7H2O

Procedure preparation of the calibration curves

Dilute Benzoic Acid 1000mg/l and Sorbic Acid 1000mg/l stock solutions with extraction solutions. To obtain the standard mixture solutions. Concentrations of $5 \mathrm{mg} / \mathrm{l}$ to $150 \mathrm{mg} / \mathrm{l}$ respectively. Inject $10 \mathrm{l}$ of each of the calibrations solutions into the chromotograph under the following conditions. Flow rate $1.2 \mathrm{ml} / \mathrm{min}$. Wavelength for UV detection $235 \mathrm{~nm}$. Prepare the calibrations curves by plotting the peak areas against BA and SA concentration in mg per litre.

\section{Determination}

Inject $10 \mu \mathrm{l}$ of the test solutions into the chromatograph using the same conditions as for the preparation of the calibration graph. Calculation for determination the concentration of BA and/or SA of the sample CS in mg per liter, using the following equation. Concentration of BA or SA in the test sample $(\mathrm{mg} / \mathrm{kg})$, Cs

$$
C s=\frac{\mathrm{Xb} / \mathrm{Xs} \times 100 \times 1000}{1000 \mathrm{xW}}
$$

Where, $\mathrm{Xb}$ is concentration of BA in the test solution obtained directly from the calibration curve. Ws is the test samples in grams.

\section{Validation of analytical method}

The analytical method was assessed for linearity, recovery, precision, and limit of detection before sample analysis.

\begin{tabular}{|c|c|c|}
\hline Product & Sorbic acid (mg/kg) & Benzoic acid (mg/kg) \\
\hline Rsd 1 & nd & 318 \\
\hline Rsd 2 & nd & 277 \\
\hline Rsd 3 & nd & 140 \\
\hline Rsd 4 & 78 & 478 \\
\hline Rsd 5 & 33 & 120 \\
\hline Rsd 6 & 102 & 151 \\
\hline Rsd 7 & nd & 375 \\
\hline Rsd 8 & nd & 169 \\
\hline Rsd 9 & nd & 419 \\
\hline Rsd 10 & nd & 158 \\
\hline Rsd 11 & 142 & 145 \\
\hline Rsd 12 & nd & 374 \\
\hline Rsd 13 & nd & 585 \\
\hline Rsd 14 & nd & 368 \\
\hline Rsd 15 & nd & 175 \\
\hline Rsd 16 & nd & 43 \\
\hline Rsd 17 & 23 & 138 \\
\hline Rsd 18 & nd & 390 \\
\hline Rsd 19 & nd & 212 \\
\hline Rsd 20 & nd & 55 \\
\hline Rsd 21 & 46 & 42 \\
\hline Rsd 22 & nd & 113 \\
\hline Rsd 23 & 60 & 318 \\
\hline Rsd 24 & 80 & 86 \\
\hline Rsd 25 & nd & 322 \\
\hline Rsd 26 & nd & 352 \\
\hline Rsd 27 & 23 & 138 \\
\hline Rsd 28 & nd & 631 \\
\hline Rsd 29 & 46 & 42 \\
\hline Rsd 30 & nd & 432 \\
\hline
\end{tabular}

\section{Result and Discussions}

Table 2: Preservatives content in ready to serve drinks. 


\begin{tabular}{|c|c|c|}
\hline Product & $\begin{array}{c}\text { Sorbic Acid } \\
\text { (mg/kg) }\end{array}$ & $\begin{array}{c}\text { Benzoic Acid } \\
\text { (mg/kg) }\end{array}$ \\
\hline J 1 & nd & 52 \\
\hline J 2 & nd & 446 \\
\hline J 3 & nd & 451 \\
\hline J 4 & nd & 146 \\
\hline J 5 & nd & 345 \\
\hline J 6 & nd & 49 \\
\hline J 7 & nd & 81 \\
\hline J 8 & 66 & 259 \\
\hline J 9 & nd & 584 \\
\hline J 10 & nd & 30 \\
\hline J 11 & nd & 81 \\
\hline J 12 & nd & 769 \\
\hline J 13 & nd & 575 \\
\hline J 14 & nd & 664 \\
\hline J 15 & nd & 368 \\
\hline J 16 & nd & 65 \\
\hline J 17 & nd & 55 \\
\hline J 18 & nd & 44 \\
\hline J 19 & 63 & 58 \\
\hline J 20 & nd & 866 \\
\hline
\end{tabular}

Table 3: Preservatives content in Jam.

\begin{tabular}{|c|c|c|}
\hline Product & $\begin{array}{c}\text { Sorbic } \\
\text { Acid(mg/kg) }\end{array}$ & $\begin{array}{c}\text { Benzoic } \\
\text { Acid(mg/kg) }\end{array}$ \\
\hline N1 & 59 & nd \\
\hline N2 & 192 & 45 \\
\hline N3 & nd & 51 \\
\hline N4 & 31 & nd \\
\hline N5 & nd & 83 \\
\hline N6 & nd & 44 \\
\hline N7 & 36 & 40 \\
\hline N8 & nd & 164 \\
\hline N9 & nd & 184 \\
\hline N10 & nd & 288 \\
\hline
\end{tabular}

\begin{tabular}{|c|c|c|}
\hline Product & $\begin{array}{c}\text { Sorbic Acid Content } \\
\text { (mg/kg) }\end{array}$ & $\begin{array}{c}\text { Benzoic Acid } \\
\text { Content(mg/kg) }\end{array}$ \\
\hline CB 1 & 165 & nd \\
\hline CB 2 & nd & 130 \\
\hline CB 3 & nd & 118 \\
\hline CB 4 & 69 & 190 \\
\hline CB 5 & nd & 194 \\
\hline CB 6 & nd & 219 \\
\hline CB 7 & nd & 199 \\
\hline CB 8 & nd & 225 \\
\hline CB 9 & nd & 126 \\
\hline CB 10 & nd & 219 \\
\hline
\end{tabular}

Table 5: Preservatives Content in Carbonated Beverages.

\begin{tabular}{|c|c|c|}
\hline Product & $\begin{array}{c}\text { Sorbic Acid } \\
\text { Content(mg/kg) }\end{array}$ & $\begin{array}{c}\text { Benzoic Acid } \\
\text { Content(mg/kg) }\end{array}$ \\
\hline JC 1 & 149 & nd \\
\hline JC 2 & 84 & 219 \\
\hline JC 3 & 238 & nd \\
\hline JC 4 & 192 & 155 \\
\hline JC 5 & 184 & 52 \\
\hline JC 6 & 16 & 44 \\
\hline JC 7 & 292 & nd \\
\hline JC 8 & 333 & 380 \\
\hline JC 9 & 314 & 444 \\
\hline JC 10 & 30 & 211 \\
\hline
\end{tabular}

Table 6: Preservatives Content in Jelly Cups.

\begin{tabular}{|c|c|c|}
\hline Product & $\begin{array}{c}\text { Sorbic Acid Content } \\
\text { (mg/kg) }\end{array}$ & $\begin{array}{c}\text { Benzoic Acid Content } \\
\text { (mg/kg) }\end{array}$ \\
\hline Jd 1 & 90 & nd \\
\hline Jd 2 & nd & nd \\
\hline Jd 3 & 215 & 297 \\
\hline Jd 4 & 215 & nd \\
\hline Jd 5 & 182 & nd \\
\hline Jd 6 & nd & 239 \\
\hline Jd 7 & 582 & 192 \\
\hline Jd 8 & 142 & nd \\
\hline Jd 9 & 90 & 59 \\
\hline Jd 10 & 120 & nd \\
\hline
\end{tabular}

Table 7: Preservative content in Jelly Drink. 
Levels of Benzoic and Sorbic Acid Preservatives in Commercially Produced Ready to Serve Products in Sri Lanka

\begin{tabular}{|l|c|c|}
\hline Product & $\begin{array}{c}\text { Sorbic acid } \\
\text { (mg/kg) }\end{array}$ & $\begin{array}{c}\text { Benzoic Acid } \\
\text { (mg/kg) }\end{array}$ \\
\hline SA 1 & nd & 337 \\
\hline SA 2 & nd & 338 \\
\hline SA 3 & nd & 75 \\
\hline SA 4 & nd & 178 \\
\hline SA 5 & nd & 330 \\
\hline SA 6 & 164 & 214 \\
\hline SA 7 & nd & 1120 \\
\hline SA 8 & 204 & 172 \\
\hline SA 9 & nd & 205 \\
\hline SA 10 & nd & 422 \\
\hline
\end{tabular}

Table 8: Preservative content in Sauces.

In table 2 to 8 shown the different content of Benzoic Acid and Sorbic Acid in all the 100 samples of carbonated Beverages, jams, jelly drinks, jelly cups, nectars, sauces, and ready to serve drinks. The each level of the preservatives tested were in compliance with the Food Act and Food Standards Regulations in Sri Lanka.

According to Sri Lanka Standard 729:2010 ready to serve drinks means A fruit drink intended for consumption without dilution and prepared from unfermented but fermentable fruit juice/ puree/concentrate with or without some of the pulp and containing any soluble sweetener and portable water. For ready to serve drinks the legal limits of Benzoic acid was found to be $160 \mathrm{mg} / \mathrm{kg}$ and sorbic acid $300 \mathrm{mg} / \mathrm{kg}$. In ready to serve drinks the range of Sorbic Acid content (19-478) mg/kg and Benzoic acid range (42$318) \mathrm{mg} / \mathrm{kg}$. Out of 30 samples Sorbic Acid was not detected in 20 samples and Benzoic Acid detected in all the However in product 6 the concentration of BA is 151 and percentage of BA is $94 \%$ and SSA 34\%. This sample also not compliance with the Food Standard Regulations in 1989. According to Food Preservatives Regulations 1989 if product contained combination of preservatives the total percentage of those preservatives shall not exceed hundred. According to the legal requirements, from them out of 30 samples 18 samples are violate.

According the SLS (265:1985) jams means the wholesome product obtained by processing to a suitable consistency, fruit ingredients which may be all fruit, fruit pulp or fruit puree, with water and a carbohydrate sweetner. According to schedule ii of Food Preservatives Regulations 1989, of Food Act and Regulations of Sri

Lanka Benzoic Acid is not a permitted preservatives in jam. But Sorbic Acid allowed upto $350 \mathrm{mg} / \mathrm{kg}$. The results of the analyses of the jam are collected in Table 3. In all the samples Sorbic Acid was not detected. Benzoic Acid detected in the range of (30-866) mg/kg. However the Benzoic Acid detected in all the samples. Out of 20 samples all the samples were poor quality.

According to SLS 1328: 2008 fruit Nectar means the unfermented but fermentable product obtained by adding water with or without the addition of sugars honey treacle and or syrups and or non nutritive sweetners to product given in fruit juices or mixture of those products. In the majority of the samples sorbic acid was detected in the range of (31-192) $\mathrm{mg} / \mathrm{kg}$ and it was not detected in 6 samples. The Benzoic Acid was detected in the range of (40-288) $\mathrm{mg} / \mathrm{kg}$ and not detected in 2 samples. Another thing according to SLS Requirements (SLS 1328:2008) nectar shall not contain any added artificial colours. According to Table 410 samples were tested, From these, 3 samples were contained benzoic acid that above the legal limits of $160 \mathrm{mg} / \mathrm{kg}$.

From SLS (183:1997) carbonated beverages means ready to drink nonalcoholic beverages prepared from portable water one or more of the ingredients given in sweetening ingredients, fruit juices, flavouring agents, like this saturated with carbon dioxide and packed in hermitically sealed containers. These may be plain, flavoured or sweetened. 10 samples were tested In table 5 is shown the average content of BA and SA in all the samples. For carbonated Beverages the legal limits of BA was found to be $160 \mathrm{mg} / \mathrm{kg}$ and Sorbic Acid 300mg/kg. According to these 6 samples were not compliance of the Food Act. According to results of the range of BA (126225)mg/kg. But Sorbic Acid was detected in two samples however the BA detected in 9 samples. Out of 10 samples 6 samples were not agree for the Standard Regulations and Act in 1989.

According to SLS standards jelly means the product prepared from a suitable fruit ingredients from which the insoluble solids have been removed during the process of manufacture and mixed with a carbohydrate sweetner with or without water and processed to a semi solid consistency. According to schedule ii of Food (preservatives) Regulations 1989 jelly (jelatine base sugar confectionery) is not a specified food article which may contain permitted preservatives. In table 6 shown the results of the analyses of jelly samples, the relavant range of Sorbic Acid (16-333) mg/kg and Benzoic Acid (52-444)mg/kg However the Sa and BA are accidentally exceeded, 
which does not allowed which stated in Food Standard Regulations. All the samples were poor quality.

Actually for jelly drinks the legal limits of BA was found to be $160 \mathrm{mg} / \mathrm{kg}$ and SA $300 \mathrm{mg} / \mathrm{kg}$. The results of the analyses of jelly drinks samples were collected in Table 7. The SA was detected in all the samples in the of $90-582 \mathrm{mg} / \mathrm{kg}$. Additionally the concentration of BA was found in most of the samples contained in the range of $59-297 \mathrm{mg} / \mathrm{kg}$.

According to schedule ii of Food (Preservatives) Regulation 1989 , for soft drinks, further if product contain more than one preservative sum of the percentage of those preservatives shall not exceed 100. But in jelly drink product 3 the concentration of BA is 297, percentage BA 185, and for SA 215, concentration SA 72 percentage. This sample also not compliance with the Food Standards Regulation in 1989. In jelly drinks also 3 samples were not compliance of the Food Act and Regulations.

For sauces we are analyzed in 3 kinds of sauces Tomato sauces, Chilli sauces, Soya sauces. According to schedule ii of Food (Preservatives) Regulation 1989 sauces shall not contain more than $250 \mathrm{mg} / \mathrm{kg}$ BA and $1000 \mathrm{mg} / \mathrm{kg} \mathrm{SA}$. The results of the analyses of the sauce samples were collected in Table 8. The BA was detected in all the samples in the range of (75 to 1120 ) $\mathrm{mg} / \mathrm{kg}$, while the SA was not detected in all the samples, except product 6 and 8 , out of 10 samples 5 products are accidentally exceeded the permitted values in Food Standards Regulations [1-6].

\section{Conclusion}

The analyses of Benzoic Acid and Sorbic Acid content in 100 samples of different food products were performed by using RPHPLC. This method enables the simultaneous and selective analyses of these popular preservatives in different types of products. Among them $65 \%$ of samples do not compliance with Food Standard Regulation.

\section{Acknowledgements}

My gratefully acknowledge the financial assistant of my dearest brother, Dr. H. W. S. Nishendra Karunarathne Consultant Gyneocologist and Obs. Lanka Hospital in Colombo, Sri Lanka.
Bibliography

1. Food Act and Regulations of Sri Lanka

2. SLS Standards (1328:2008), (183:2007), (265:1985), (729:2010).

3. School of science, University Greenwich, Old Royal Naval College, 30 park Row London SE 10 9LS, UK.

4. Head of Food Additives Department at Central Lab of Residue Analysis of Pesticides and Heavy metals in Food, (QCAP Lab).

5. Analytical Chemist at Central Lab of Residue analysis of Pesticides and Heavy metals in Food, (QCAP Lab).

6. MGMH Elsayed., et al. "Department of Sorbic Acid and Benzoic Acid using RP-HPLC in Different Food Commodities, Pharm Analysis and Quality Assurance 2917 (2017): 1-5.

\section{Volume 3 Issue 8 August 2019}

(C) All rights are reserved by Krishanthi Karunarathne. 